\title{
Evaluation of Various Scoring Systems in Prediction of Acute Carbon Monoxide Poisoning Outcome
}

\author{
Elhawary AE and Sagah GA ${ }^{1}$
}

${ }^{1}$ Department of Forensic Medicine and Clinical Toxicology, Faculty of Medicine, Tanta University, Tanta, Egypt.

\begin{abstract}
Background: Carbon monoxide (CO) poisoning is one of the most common fatal poisoning worldwide. Laboratory parameters and imaging studies have been used to predict late cardiac and neurological complications in $\mathrm{CO}$ poisoned patients. However, very few studies have applied scoring systems as predictors of $\mathrm{CO}$ poisoning outcome. Objectives: To evaluate various scoring systems used in emergency settings [Rapid Emergency Medicine Score (REMS), Modified Early Warning Score (MEWS) and Simple Clinical Score (SCS)] for outcome prediction in acute CO poisoned patients. Methodology: It was a cross-sectional study that was conducted on forty five acute $\mathrm{CO}$ poisoned patients. It was composed of two parts; retrospective (From $1^{\text {st }}$ of January 2020 to $28^{\text {th }}$ of February 2021) and prospective part (From $1^{\text {st }}$ of March 2021 to $30^{\text {th }}$ of June 2021). Patients with major medical conditions, pregnant females, smokers and those exposed to associated trauma and other substances in addition to CO were excluded. Using patients' data on admission, REMS, MEWS and SCS were calculated and compared for prediction of outcome. Results: On admission REMS, MEWS and SCS showed significant elevation in both mechanically ventilated and non-survivors when compared to nonmechanically ventilated patients and survivors. MEWS was excellent predictor for requirement of mechanical ventilation (AUC > 0.9). For mortality prediction; REMS, MEWS and SCS were all excellent (AUC = 1). Conclusion: REMS, MEWS and SCS are simple, rapid, reliable and applicable scoring system in predicting mechanical ventilation requirement and in-hospital mortality in acute $\mathrm{CO}$ poisoning.
\end{abstract}

Received in original form: 31 August $2021 \quad$ Accepted in a final form: 13 october 2021

Key words Carbon monoxide (CO) poisoning, REMS score, MEWS and SCS scores, Mechanical ventilation, Mortality

\section{Introduction}

$\longrightarrow$ arbon monoxide $(\mathrm{CO})$ poisoning is one of the most common fatal air born poisoning worldwide colorless gas, emitted by incomplete ignition of carbonaceous substances. Victims become comatose before realizing they are being poisoned (Rose et al., 2017).

Toxicity results from a combination of tissue hypoxia and direct carbon monoxide mediated damage at cellular level (Lai et al., 2016). Clinical presentation in patients with $\mathrm{CO}$ poisoning ranges from headache and dizziness to seizures, coma and death (Liao et al., 2019). Results of CO poisoning on humans are not always the same (Stucki and Stahl, 2020).

Laboratory parameters and imaging studies have been used to predict late cardiac and neurological complications with long term sequel (Lin et al., 2018). However, very few studies have applied scoring system to evaluate clinical features and laboratory tests as predictors of $\mathrm{CO}$ poisoning outcome (El-Gharbawy and Khalifa, 2019 \& Wang et al., 2019).

Using scoring systems in medical practice usually support clinical decision making. They enable the physicians to diagnose diseases, assess patients' conditions and predict the outcome In emergency situations scoring systems tend to be simple and based mainly on clinical data with no or minimal incorporation of investigations (Oprita et al., 2014).

Many scores have been developed and validated for use in emergency department (Brabrand et al., 2010). The aim of this study was to evaluate various scoring systems used in emergency settings [Rapid Emergency Medicine Score (REMS), Modified Early Warning Score (MEWS) and Simple Clinical Score (SCS)] for outcome prediction in acute carbon monoxide poisoned patients.

\section{Patients and Methods}

This cross-sectional study was carried out on acute carbon monoxide intoxicated patients admitted to Tanta Poison Control Center, Tanta Emergency University Hospital. It was composed of two parts; retrospective (From $1^{\text {st }}$ of January 2020 to $28^{\text {th }}$ of February 2021) and prospective part (from $1^{\text {st }}$ of March 2021 to $30^{\text {th }}$ of June 2021).

All patients above 12 years old, acutely intoxicated by $\mathrm{CO}$ were included in this study. Diagnosis of acute carbon monoxide intoxication was done depending on history of $\mathrm{CO}$ exposure, clinical findings (such as alteration in consciousness level, syncope, seizures, shortness of breath, chest pain and 
palpitation) and/or carboxyhaemoglobin ( $\mathrm{COHb} \%)$ level $>5 \%$ in non-smokers or $>10 \%$ in smokers (Hampson et al., 2012 \& Rose et al., 2017).

Patients with major medical conditions (e.g. cardiovascular disease, chronic obstructive pulmonary disease, renal or hepatic failure), pregnant females and smokers were excluded. Furthermore, patients who received any medications before admission and those exposed to associated trauma and other substances in addition to carbon monoxide were excluded. Retrospective patients with essential missed data were also excluded.

Sociodemographic data (including age, gender and residence) and toxicological data (including mode of exposure and time elapsed before hospital admission) were collected. Vital signs (Pulse, blood pressure, respiratory rate and temperature) and consciousness level were assessed and reported on admission. Investigations included; Electrocardiogram (ECG), blood oxygen saturation (using pulse oximeter) and blood carboxyhaemoglobin (using Rad.57 Signal Extraction Pulse CO-Oximeter device) (Masimo Rainbow SET (C), USA).

The followin5g scoring systems were compared for outcome prediction in acute carbon monoxide poisoned patients:

1. Rapid emergency medicine score (REMS) using pulse rate, mean arterial pressure, respiratory rate, GCS, age and oxygen saturation. The minimum score is zero, while the maximum score is 26 by (Olsson et al., 2004a)

2. Modified Early Warning Score (MEWS) using respiratory rate, oxygen saturations, temperature, systolic blood pressure, pulse rate, level of consciousness (using AVPU scale) with a minimum score of zero and a maximum score of 14 (Kelly et al., 2004).

3. Simple clinical score (SCS) using the age, airway condition, breathing, circulation, disability, ECG, and temperature. The minimum score is zero and the maximum score is 21 (Subbe et al., 2010).

The previous scoring systems were compared for prediction of short-term outcome of all included patients. Primary outcome was in-hospital mortality; secondary outcome was need for mechanical ventilation (MV).

This study was conducted following approval from medical research ethical committee in Tanta Faculty of Medicine. All prospective patients (or their guardians) were asked to provide informed written consent for participation after receiving detailed information about the study. File records of retrospective patients were revived after administration approval. Patients' privacy, data confidentiality and the investigations results were maintained by using coding number.

Statistical analysis: MedCalc Statistical Software version 15.8 was used to analyze the collected data. The distribution of numerical data was determined according to the Shapiro-Wilk test for normality. Numerical data were summarized as mean \pm standard deviation (SD) for normally distributed variables or as the median and interquartile range
(IQR: 25th - 75th percentiles) for abnormally distributed variables. The comparison of the studied scores between two independent groups was done using the Mann-Whitney test. Spearman's rank-order correlation was performed to assess the relationship between the scores and relevant numerical variables. The categorical variables were summarized as frequencies. Receiver operating characteristics (ROC) curve was performed to identify the optimal cut-off point, sensitivity, specificity, positive and negative predictive values (PPV and NPV) for the studied scores. The area under the curve (AUC) was graded excellent (0.90-1.00), good (0.80-0.90), fair (0.70-0.80) and poor (0.60- 0.70).

\section{Results}

During the period of the study, 45 acute $\mathrm{CO}$ poisoned patients have fulfilled inclusion criteria. Table (1) illustrates socio-demographic and toxicological data of studied patients. The age of patients ranged between 12 and 78 years old, with a median age of 26 years. All patients were accidentally exposed to $\mathrm{CO}$, with a median delay of 2 hours before arrival.

Table (2) shows results of scoring systems used for clinical evaluation of patients. REMS, MEWS and SCS registered median values of 5, 4 and 4 respectively. Patients' oxygen blood saturation ranged from $40 \%$ to $100 \%$ with a mean value of $88.8 \pm 14.3$. On admission, carboxyhemoglobin (COHb) level ranged from $8 \%$ to $63 \%$ with a median value of $20 \%$. Figure (1) demonstrates that $53.3 \%$ of patients stayed at hospital less than 24 hours. Mechanical ventilation was required in $15.6 \%$ of patients; death was reported in $8.9 \%$.

On admission REMS, MEWS and SCS showed significant elevation in both mechanically ventilated and non-survivors when compared to non-mechanically ventilated patients and survivors as noticed in Table (3). Spearman's rank-order correlation revealed positive significant correlation between the studied scores on admission and patients' blood $\mathrm{COHb}$ level. On the other hand, duration of hospital stay had no significant correlation with any of the studied scores (Table 4).

Table (5) and figure (2) analyzed MEWS as excellent predictor for requirement of mechanical ventilation in receiver operating characteristics (ROC) curve, (AUC > 0.9) with $100 \%$ sensitivity at cut off value $>4$ (specificity 65.8\%). Good negative and positive predictive values were found in REMS and SCS (AUC > 0.8) with $100 \%$ and $57.1 \%$ sensitivity at cut off levels $>4$ and 9 respectively (specificity $57.9 \%$ and $100 \%$ respectively). For mortality prediction; REMS, MEWS and SCS were all excellent $(\mathrm{AUC}=1)$ with $100 \%$ sensitivity and specificity at cut off levels > 11, 7 and 9 respectively. 
(38): $79-86$

Table (1): Age, Gender, residence and delay hours of acutely poisoned patients with carbon monoxide $(\mathrm{N}=45)$.

\begin{tabular}{|c|c|c|c|}
\hline Age (years) & Median [IQR] (Min-Max) & \multicolumn{2}{|c|}{$26[20-44](12-78)$} \\
\hline \multirow{2}{*}{ Gender } & Male & 27 & $60 \%$ \\
\cline { 2 - 4 } & Female & 18 & $40 \%$ \\
\hline \multirow{2}{*}{ Residence } & Rural & 34 & $75 \%$ \\
\cline { 2 - 4 } & Urban & 11 & $24.4 \%$ \\
\hline \multirow{2}{*}{ Delay (hours) } & Median [IQR] (Min-Max) & \multicolumn{2}{|c|}{$2[1-4](1-10)$} \\
\hline
\end{tabular}

IQR: interquartile range; Max: maximum; Min: minimum; SD: standard deviation

Table (2): Scoring systems, $\mathrm{O} 2$ saturation, Co level on admission of acutely poisoned patients with carbon monoxide $(\mathbf{N}=45)$.

\begin{tabular}{|c|c|c|}
\hline REMS & $\begin{array}{c}\text { Median } \\
\text { [IQR }] \\
\text { (Min-Max) }\end{array}$ & $\begin{array}{c}5 \\
{[2-8]} \\
(0-20)\end{array}$ \\
\hline MEWS & $\begin{array}{c}\text { Median } \\
\text { [IQR] } \\
\text { (Min-Max) }\end{array}$ & $\begin{array}{c}4 \\
{[2-6]} \\
(0-10)\end{array}$ \\
\hline SCS & $\begin{array}{c}\text { Median } \\
\text { [IQR }] \\
\text { (Min-Max) }\end{array}$ & $\begin{array}{c}4 \\
{[2-8]} \\
(0-10)\end{array}$ \\
\hline $\mathrm{O}_{2}$ saturation $(\%)$ & $\begin{array}{l}\text { Mean } \pm \text { SD } \\
\text { (Min-Max) }\end{array}$ & $\begin{array}{c}88.8 \pm 14.3 \\
(40-100)\end{array}$ \\
\hline CO level (\%) & $\begin{array}{c}\text { Median } \\
\text { [IQR] } \\
\text { (Min-Max) }\end{array}$ & $\begin{array}{c}20 \\
{[12-28]} \\
(8-63)\end{array}$ \\
\hline
\end{tabular}

REMS: Rapid Emergency Medicine Score, MEWS: Modified Early Warning Score, SCS: Simple Clinical Score, O2: Oxygen, CO: carbon monoxide. IQR: interquartile range, Max: maximum; Min: minimum; SD: standard deviation.

Table (3): Comparison of scoring systems on admission between patients categorized according to the need of mechanical ventilation and mortality in acute carbon monoxide poisoning $(\mathrm{N}=45)$ using MannWhitney test.

\begin{tabular}{|c|c|c|c|c|c|c|c|c|c|}
\hline & \multicolumn{2}{|c|}{$\begin{array}{l}\text { Mechanical } \\
\text { ventilation }\end{array}$} & \multicolumn{2}{|c|}{$\begin{array}{c}\text { Mann-Whitney } \\
\text { test }\end{array}$} & \multicolumn{2}{|c|}{ Mortality } & \multicolumn{2}{|c|}{$\begin{array}{c}\text { Mann-Whitney } \\
\text { test }\end{array}$} \\
\hline & & Yes & No & $\mathbf{Z}$ & p & yes & No & $\mathbf{Z}$ & $\mathbf{P}$ \\
\hline REMS & $\begin{array}{c}\text { Median } \\
\text { [IQR] } \\
\text { (Min-Max) }\end{array}$ & $\begin{array}{c}17.0 \\
{[7-18]} \\
(5-20)\end{array}$ & $\begin{array}{c}4.0 \\
{[2-7]} \\
(0-11)\end{array}$ & 3.139 & $0.001 *$ & $\begin{array}{c}18 \\
{[17-19]} \\
(17-20)\end{array}$ & $\begin{array}{c}4 \\
{[2-7]} \\
(0-11)\end{array}$ & 3.294 & $<0.001 *$ \\
\hline MEWS & $\begin{array}{c}\text { Median } \\
\text { [IQR] } \\
\text { (Min-Max) }\end{array}$ & $\begin{array}{c}8 \\
{[6-10]} \\
(5-10)\end{array}$ & $\begin{array}{c}3 \\
{[2-5]} \\
(0-7)\end{array}$ & 3.549 & $<0.001 *$ & $\begin{array}{c}10 \\
{[9-10]} \\
(8-10)\end{array}$ & $\begin{array}{c}4 \\
{[2-6]} \\
(0-7)\end{array}$ & 3.294 & $<0.001 *$ \\
\hline SCS & $\begin{array}{c}\text { Median } \\
\text { [IQR] } \\
\text { (Min-Max) }\end{array}$ & $\begin{array}{c}10 \\
{[5-10]} \\
(4-10)\end{array}$ & $\begin{array}{c}3 \\
{[1-7]} \\
(0-9)\end{array}$ & 2.851 & $0.003 *$ & $\begin{array}{c}10 \\
{[10-10]} \\
(10-10)\end{array}$ & $\begin{array}{c}3 \\
{[1-6]} \\
(0-9)\end{array}$ & 3.290 & $<0.001 *$ \\
\hline
\end{tabular}

REMS: Rapid Emergency Medicine Score, MEWS: Modified Early Warning Score, SCS: Simple Clinical Score, IQR: interquartile range; Max: maximum; Min: minimum; * significant at $p<0.05 *$

Table (4): Spearman's rank-order correlation between scoring systems on admission and the duration of hospital stay of acutely poisoned patients with carbon monoxide $(\mathrm{N}=45)$

\begin{tabular}{|c|c|c|c|}
\hline \multicolumn{2}{|c|}{} & Duration of hospital stay & CO level (\%) \\
\hline \multirow{2}{*}{ REMS } & $\mathrm{r}_{\mathrm{s}}$ & 0.267 & 0.486 \\
\cline { 2 - 4 } & $\mathrm{p}$ & 0.076 & $0.001^{*}$ \\
\hline \multirow{2}{*}{ MEWS } & $\mathrm{r}_{\mathrm{s}}$ & 0.109 & 0.340 \\
\cline { 2 - 4 } & $\mathrm{p}$ & 0.477 & $0.022^{*}$ \\
\hline \multirow{2}{*}{ SCS } & $\mathrm{r}_{\mathrm{s}}$ & 0.235 & 0.415 \\
\cline { 2 - 4 } & $\mathrm{p}$ & 0.120 & $0.005^{*}$ \\
\hline
\end{tabular}

REMS: Rapid Emergency Medicine Score, MEWS: Modified Early Warning Score, SCS: Simple Clinical Score, rs: coefficient of Spearman's rank-order correlation; * significant at $p<0.05$. 
(38): 79-86

Table (5): Diagnostic performance of REMS, MEWS \& SCS in prediction the need for mechanical ventilation and mortality by receiver operating characteristic (ROC) curve analysis.

\begin{tabular}{|c|c|c|c|c|c|c|c|c|}
\hline & AUC & $\mathbf{( 9 5 \%}$ CI) & p & Cut-off value & Sensitivity(\%) & Specificity(\%) & PPV(\%) & NPV(\%) \\
\hline \multicolumn{7}{|c|}{ Mechanical ventilation } \\
\hline REMS & 0.874 & $0.741-0.954$ & $<0.001^{*}$ & $>4$ & 100.0 & 57.9 & 30.4 & 100 \\
\hline MEWS & 0.923 & $0.803-0.981$ & $<0.001^{*}$ & $>4$ & 100.0 & 65.8 & 35.0 & 100 \\
\hline SCS & 0.840 & $0.700-0.932$ & $<0.001^{*}$ & $>9$ & 57.1 & 100 & 100 & 92.7 \\
\hline \multicolumn{7}{|c|}{ Mortality } \\
\hline REMS & 1 & $0.921-1$ & $<0.001^{*}$ & $>11$ & 100 & 100 & 100 & 100 \\
\hline MEWS & 1 & $0.921-1$ & $<0.001^{*}$ & $>7$ & 100 & 100 & 100 & 100 \\
\hline SCS & 1 & $0.921-1$ & $<0.001^{*}$ & $>9$ & 100 & 100 & 100 & 100 \\
\hline
\end{tabular}

REMS: Rapid Emergency Medicine Score, MEWS: Modified Early Warning Score, SCS: Simple Clinical Score, AUC: area under ROC curve; CI: confidence interval; *significant at $p<0.05$

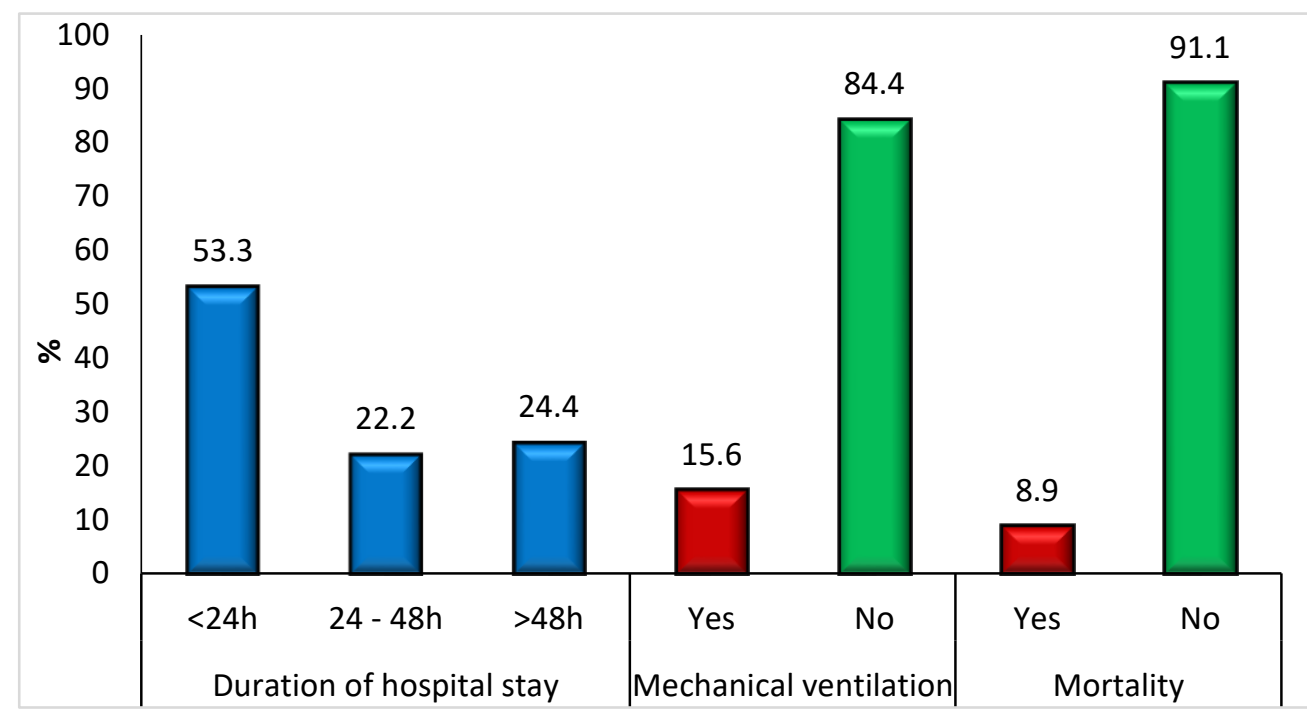

Fig. (1): Outcome of acutely poisoned patients with carbon monoxide $(\mathrm{N}=45)$.
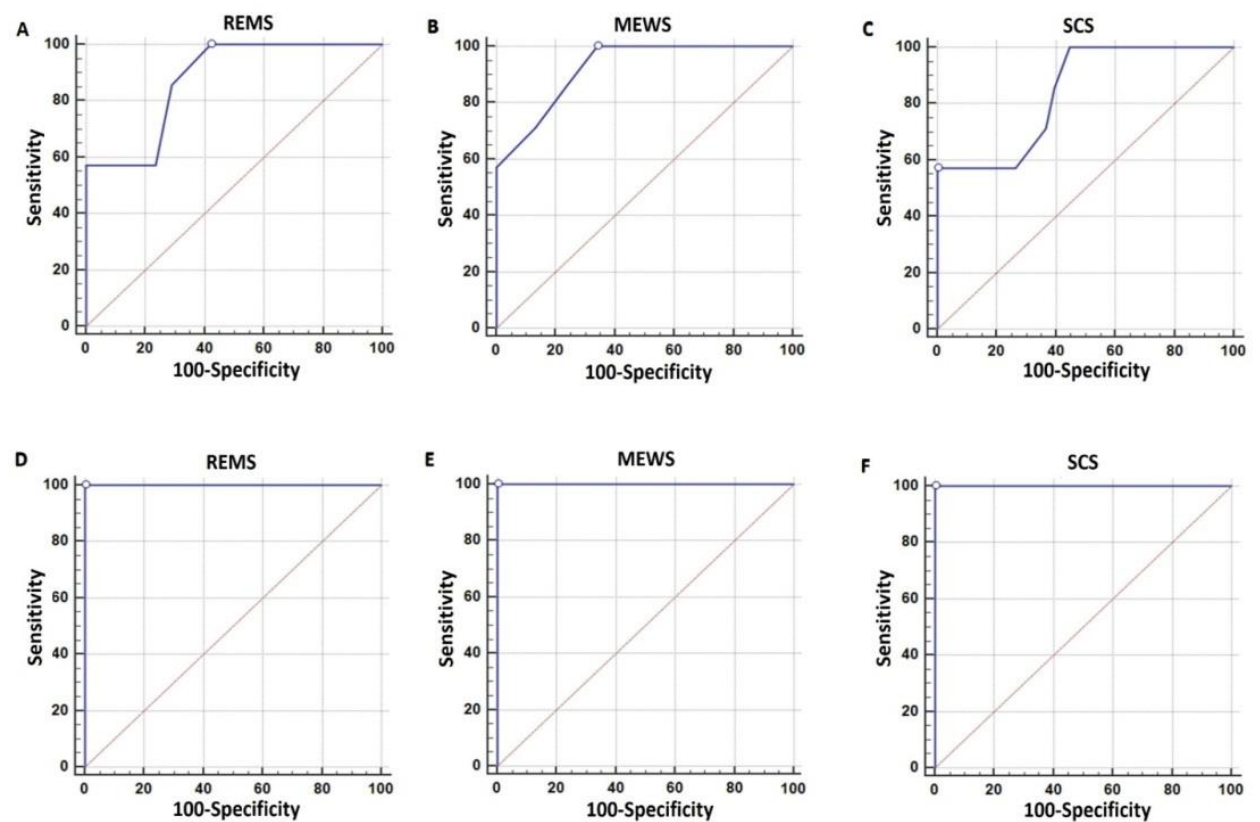

Fig. (2): Receiver Operating Characteristic (ROC) curve analysis for Rapid Emergency Medicine Score (REMS), Modified Early Warning Score (MEWS), and Simple Clinical Score (SCS) as predictors of mechanical ventilation $(\mathrm{A}, \mathrm{B}, \& \mathrm{C}$, respectively) and mortality $(\mathrm{D}, \mathrm{E}, \mathrm{\&} \mathrm{F}$, respectively). 


\section{Discussion}

$\mathrm{CO}$ poisoning is known to have several complication and high fatality rate. However, they are potentially preventable if they are early recognized and adequately treated (Tabrizian et al., 2018). Prediction of complications in $\mathrm{CO}$ poisoned patients is believed to be a challenging task. Hence, this study was designed to evaluate different scoring systems as predictors of severity, course and prognosis of carbon monoxide poisoning.

The present study revealed that, sociodemographic \& toxicological data, clinical presentation and $\mathrm{COHb}$ level in the studied patients were more or less in agreement with data gathered by comparable researches in Egypt and worldwide (Ghosh et al., 2016; Sikary et al., 2017; Huang et al., 2017; El-Gharbawy and Khalifa, 2019 \& Roca-Barceló et al., 2020).

In the current study, REMS has recorded a median value of 5 . The REMS was introduced by (Olsson et al., 2004a), for mortality rate prediction among nonsurgical patients. It incorporates age, heart \& respiratory rate, blood pressure, Glasgow Coma Scale (GCS) and oxygen saturation. According to ( $\mathrm{Hu}$ et al., 2020). In emergency situations, REMS was effective in risk stratification for critically ill patients, which was attributed to its high negative predictive value.

Significant elevation was detected in REMS parameters in both mechanically ventilated and died patients when compared to non-mechanically ventilated patients and survivors. A result that agrees with (Olsson et al., $2004_{b}$ ) , (Abd Elghany et al., 2018) \& (El-Gharbawy and Khalifa, 2019) who recorded significantly higher REMS values in non-survivors in comparison with survivors. Furthermore, (Cattermole et al., 2009) recorded significant increase of REMS in patients who needed ICU or died when compared to those who had better prognosis.

In the current study, REMS was good predictor for requirement of mechanical ventilation at cut off value $>4$. This matches with (Olsson and Lind, 2003), (Goodacre, Turner and Nicholl, 2006), (El-Sarnagawy and Hafez, 2017) \& (Abd Elghany et al., 2018) who supposed REMS as a valuable scoring system that tends to be a good predictor of morbidity and duration of hospitalization in patients admitted to the Emergency department (ED).

Furthermore, El-Sarnagawy and Hafez (2017) reported that REMS was a good predictor for mechanical ventilation in drug-overdosed patients with disturbed conscious level. Such finding comes in line with results obtained in the current study where REMS registered $100 \%$ sensitivity i.e. REMS was able to predict all patients who needed mechanical ventilation.

REMS registered excellent mortality prediction at cut off level $>11$ in this study. However, at the same cut off level it was found to be good predictor for mortality in non-surgical patients admitted to ED according to (Olsson et al. $2004_{b}$, \& Chang et al. 2018 \& El-Gharbawy and Khalifa 2019).

In the present study MEWS has recorded a median value of 4 . Xie et al. (2018) supposed MEWS as a simple tool, designed for bedside assessment of critically ill patients by nursing staff in a busy clinical area. It is a defined judgment based on routinely recorded physiological parameters including systolic blood pressure, respiratory rate, pulse rate, temperature and AVPU score. It is able to identify patients at risk of deterioration and in need of further medical intervention.

Subbe et al., (2003), Reini et al. (2012) \& Kirsch et al. (2020); Identified MEWS components with strong correlation to the need for ICU admission. These components include lower systolic blood pressure and increased both heart rate and respiratory rate. Considering these data, it was expected to find significant elevation in MEWS parameters in both mechanically ventilated and non-survivors when compared to non-mechanically ventilated patients and survivors.

In the current study, MEWS was excellent predictor for requirement of mechanical ventilation at cut off value $>4$ with $100 \%$ sensitivity i.e. MEWS was able to predict all patients who needed mechanical ventilation. A result coincides with Subbe et al., (2003) $\&$ Salottolo et al. (2017) who supposed 4 as a critical score that indicate increased risk of catastrophic deterioration of patients.

According to Subbe et al., (2003) \& Kirsch et al. (2020), MEWS cut off value of 5 was modified to 7 to be more sensitive and specific record when considering ICU admission. MEWS of at least six was considered by Reini et al. (2012) as a predictor of both longer stay at ICU and mortality. Hence, several authors considered MEWS as a helpful screening tool to classify patients for further treatment on ward or ICU.

In the current study, for mortality prediction; MEWS was excellent at cut off levels $>7$. According to Xie et al. (2018) the MEWS was a good tool for inhospital mortality prediction. With higher ratio of inhospital mortality at high scores, indicating that MEWS was significantly correlated with patient mortality. This comes in line with data gathered by Kirsch et al. (2020), who found that $>7$ MEWS carried a nearly 3 -fold increased risk of mortality.

In the present study, SCS has recorded a median value of 4. It includes age, airway condition, breathing, circulation, disability, ECG, and temperature. SCS represents a useful algorithm to assist clinical judgment to prognosticate critically ill patients. It could quickly and accurately identify high risk patients who might benefit from enhanced care to avoid adverse outcomes without waiting for further investigations (Subbe et al., 2010 \& Strcede and Brabrand, 2014).

Significant elevation was detected in SCS parameters in both mechanically ventilated and died patients when compared to non-mechanically ventilated patients and survivors. This finding correlates to data gathered by Shahin and Hafez (2020) who believed that SCS was significantly different between mechanically ventilated patients and nonmechanically ventilated as well as between survivors and non-survivors. 
According to Li et al. (2012) SCS predicts mortality with acceptable accuracy and excellent discrimination. It is very accurate and predicts 30-day mortality that could be difficult to predict clinically. Nevertheless, it is more difficult to use in daily practice. In general, most fatalities are preceded by abnormalities in vital signs, that would raise the score (Stræde and Brabrand, 2014).

In the current study, SCS was good predictor for requirement of mechanical ventilation at cut off value $>9$ with $100 \%$ specificity i.e. SCS was able to predict all patients who did not need mechanical ventilation. Moreover, SCS had a positive predictive value (PPV) of $100 \%$ i.e. (the probability that a patient with SCS $>9$ will need mechanical ventilation is $100 \%$ ).

SCS was utilized by Li et al. (2012) as a risk stratification tool. It might help to indicate timeframe and to decide management plan for ICU admission. In the same time, Shahin and Hafez (2020). Registered $>3$ as a cut off value for prediction of mechanical ventilation. However, they recorded a specificity of $76 \%$ compared to $100 \%$ specificity at cut off value $>9$ in this study.

At cut off level $>9$, SCS was excellent predictor of mortality with $100 \%$ specificity and sensitivity in the current study. Stræde and Brabrand (2014).have found that, SCS was excellent in identification of patients at high risk of mortality with good accuracy. Recently, a cut off value of SCS $>4$ was registered as good mortality predictor with specificity $85 \%$ and sensitivity 86\% (Shahin and Hafez, 2020).

On admission, positive significant correlation was found between REMS, MEWS and SCS and patients' blood COHb level. Gozubuyuk et al. (2017) supposed that, symptoms of poisoning are linked to carboxyhaemoglobin level. However, Köthe and Radke (2010) considered initial COHb level as an inaccurate reflection of a patients' exposure because $\mathrm{COHb}$ levels decrease with time and with oxygen treatment. On the other hand, duration of hospital stay had no significant correlation with REMS, MEWS and SCS.

Toxicology researches lack a well-accepted method for assessing severity of $\mathrm{CO}$ poisoning in emergency department (Roca-Barceló et al. 2020 \& Han et al., 2021). The current study is unique to investigate REMS, MEWS \& SCS as a predictor of the need for ventilation and mortality in acute $\mathrm{CO}$ poisoned patients in Egypt. However, Aksu et al.( 2012) have concluded that using admission vital signs alone for outcome prediction could be misleading, as patients may present very early with quite stable vital signs.

According to data gathered in the current study, MEWS was found to be an excellent predictor of both need for mechanical ventilation and mortality. In the same time, both REMS \& SCS were found to be good predictor of need for mechanical ventilation and excellent predictor of mortality. Hence, the authors believe that MEWS will be a suitable score to help doctors to predict both need for mechanical ventilation and mortality. It would be beneficial for emergency and toxicology resident doctors to apply MEWS score in acute CO intoxicated patients so as to control need for mechanical ventilation subsequently saving hospital resources.

\section{Conclusion}

In conclusion, REMS, MEWS and SCS are simple, easy, rapid, reliable and applicable scoring system that does not consume time, require several laboratory variables which could be unavailable at admission or highly qualified personnel. Hence, they seem to be helpful in predicting mechanical ventilation requirement and in-hospital mortality in acute $\mathrm{CO}$ poisoning.

\section{Study Limitation}

Being a single center study with limited number of patients in a specific local setting is a major limitation of the current study. For technical reasons, we were unable to collect data about use of hyperbaric oxygen in treatment of included patients.

\section{Recommendations}

Further multicenter researches on larger scales with ability to follow up hyperbaric oxygen treatment are needed to confirm the results of the current study.

\section{References}

Abd Elghany S, Heshmat M, Oreby M \& Elsarnagawy G (2018): Evaluation of various scoring systems in prediction of acute aluminum phosphide (ALP) poisoning outcome. Ain Shams Journal of Forensic Medicine and Clinical Toxicology, 30 (1): 117-127.

Aksu NM, Akkaş M, Çoşkun F, Karakiliç E, Günalp M, Akküçük H, Ataman DK, Özcan H, \& Özmen MM (2012): Could Vital Signs Predict Carbon Monoxide Intoxication? Journal of International Medical Research, 40 (1): 366-370.

Brabrand M, Folkestad L, Clausen NG, Knudsen T \& Hallas J (2010): Risk scoring systems for adults admitted to the emergency department: a systematic review. Scandinavian Journal of Trauma, Resuscitation and Emergency Medicine, 18(1):8.

Cattermole GN, Mak SKP, Liow CHE, Ho MF, Hung KYG, Keung KM, Li HM, Graham CA \& Rainer TH (2009): Derivation of a prognostic score for identifying critically ill patients in an emergency department resuscitation room. Resuscitation, 80 (9): 1000-1005.

Chang SH, Hsieh CH, Weng YM, Hsieh MS, Goh ZNL, Chen HY, Chang T, Ng CJ, Seak JCY \& Seak CK (2018): Performance assessment of the Mortality in Emergency Department Sepsis Score, modified Early Warning Score, Rapid Emergency Medicine Score, and Rapid Acute Physiology Score in predicting survival outcomes of adult renal abscess patients in the emergency department. BioMed Research International, [6983568]. https://doi.org/ 10. 1155/2018/6983568.

El-Gharbawy D \& Khalifa H (2019): Assessment of Some Scoring Systems in Prediction of Mortality in Acute Carbon Monoxide Poisoned Patients. Mansoura Journal of Forensic Medicine and Clinical Toxicology, 27(1): 87-102.

El-Sarnagawy GN \& Hafez ASAF (2017): Comparison of different scores as predictors of mechanical 
ventilation in drug overdose patients. Human \& Experimental Toxicology, 36(6): 539-546.

Ghosh RE, Close R, McCann LJ, Crabbe H, Garwood K, Hansell AL \& Leonardi G (2016): Analysis of hospital admissions due to accidental nonfire-related carbon monoxide poisoning in England, between 2001 and 2010. Journal of Public Health, 38(1): 76-83.

Goodacre S, Turner J \& Nicholl J (2006): Prediction of mortality among emergency medical admissions. Emergency Medicine Journal, 23(5): 372-375.

Gozubuyuk AA, Dag H, Kaçar A, Karakurt Y \& Arica V (2017): Epidemiology, pathophysiology, clinical evaluation, and treatment of carbon monoxide poisoning in child, infant, and fetus. Northern Clinics of Istanbul, 4(1):100.

Hampson NB, Piantadosi C A, Thom SR \& Weaver LK (2012): Practice Recommendations in the Diagnosis, Management, and Prevention of Carbon Monoxide Poisoning. American Journal of Respiratory and Critical Care Medicine, 186 (11):1095-1101.

Han KS, Kim SJ, Lee EJ, Shin JH, Lee JS \& Lee SW (2021): Development and validation of new poisoning mortality score system for patients with acute poisoning at the emergency department. Critical Care, 25(1): 29.

Han S, Nah S, Choi S, Kim GW\& Lee YH (2020): Optimal sessions of hyperbaric oxygen therapy in patients with carbon monoxide poisoning: A prospective observational study. The American Journal of Emergency Medicine. https://doi.org/ 10.1016.

$\mathrm{Hu}$ H, Yao N \& Qiu Y (2020): Comparing Rapid Scoring Systems in Mortality Prediction of Critically Ill Patients with Novel Coronavirus Disease. Academic Emergency Medicine, 27(6): 461-468.

Huang CC, Ho CH, Chen YC, Lin HJ, Hsu CC, Wang JJ, Su SB \& Guo HR (2017): Demographic and clinical characteristics of carbon monoxide poisoning: nationwide data between 1999 and 2012 in Taiwan. Scandinavian Journal of Trauma, Resuscitation and Emergency Medicine, 25(1): 70 .

Kelly CA, Upex A \& Bateman DN (2004): Comparison of consciousness level assessment in the poisoned patient using the alert/ verbal/ painful/ unresponsive scale and the Glasgow Coma Scale. Annals of Emergency Medicine, 44(2): 108-113.

Kirsch N, Bessen M, Warren M, Cross C \& Dy R (2020): The Modified Early Warning Score (Mews) as A Predictor of Unanticipated ICU Admission at The Time of Rapid Response. CHEST Journal,158(4S):A641-A641.

Köthe L \& Radke J (2010): Carboxyhämoglobinkonzentration bei Kohlenmonoxidvergiftung. Der Anaesthesist, 59 (6): 529-534.

Lai CY, Huang YW, Tseng CH, Lin CL, Sung FC \& Kao CH (2016): Patients with Carbon
Monoxide Poisoning and Subsequent Dementia: A Population-Based Cohort Study. Medicine, 95(1).

Li JYZ, Yong TY, Hakendorf P, Roberts S, O’Brien L, Sharma Y, Ben-Tovim D \& Thompson CH (2012): Simple clinical score is associated with mortality and length of stay of acute general medical admissions to an Australian hospital. Internal Medicine Journal, 42(2): 160-165.

Liao WC, Cheng WC, Wu BR., Chen WC, Chen CY, Chen CH, Tu CY \& Hsia TC (2019): Outcome and prognostic factors of patients treated in the intensive care unit for carbon monoxide poisoning. Journal of the Formosan Medical Association, 118 (4): 821-827.

Lin MS, Lin CC, Yang CC, Weng SC, Wang SM, Chen CY, Huang N \& Chou YH (2018): Myocardial injury was associated with neurological sequelae of acute carbon monoxide poisoning in Taiwan. Journal of the Chinese Medical Association, 81(8): 682-690.

Olsson T \& Lind L (2003): Comparison of the Rapid Emergency Medicine Score and APACHE II in Nonsurgical Emergency Department Patients. Academic Emergency Medicine, 10(10): 10401048.

Olsson T, Terent A \& Lind L $\left(2004_{a}\right)$ : Rapid Emergency Medicine Score Can Predict Longterm Mortality in Nonsurgical Emergency Department Patients. Academic Emergency Medicine, 11(10): 1008-1013.

Olsson T, Terént A \& Lind L $\left(2004_{b}\right)$ : Rapid Emergency Medicine Score: a new prognostic tool for inhospital mortality in nonsurgical emergency department patients. Journal of Internal Medicine, 255 (5): 579-587.

Oprita B, Aignatoaie B \& Gabor-Postole DA (2014): Scores and scales used in emergency medicine. Practicability in toxicology. Journal of Medicine and Life, 7 (3): 4-7.

Reini K, Fredrikson M \& Oscarsson A (2012): The prognostic value of the Modified Early Warning Score in critically ill patients: a prospective, observational study. European Journal of Anaesthesiology, 29 (3): 152-157.

Roca-Barceló A, Crabbe H, Ghosh R, Freni-Sterrantino A, Fletcher T, Leonardi G, Hoge C, Hansell AL \& Piel FB (2020): Temporal trends and demographic risk factors for hospital admissions due to carbon monoxide poisoning in England. Preventive Medicine, 136: e106104.

Rose JJ, Wang L, Xu Q, McTiernan CF, Shiva S, Tejero J \& Gladwin MT (2017): Carbon Monoxide Poisoning: Pathogenesis, Management, and Future Directions of Therapy. American Journal of Respiratory and Critical Care Medicine, 195(5): 596-606.

Salottolo K, Carrick M, Johnson J, Gamber M \& BarOr D (2017): A retrospective cohort study of the utility of the modified early warning score for interfacility transfer of patients with traumatic injury. BMJ Open, 7(5): e016143. 
Shahin M \& Hafez A (2020): Comparison of different scoring systems in poisoning with cholinesterase inhibitors. Mansoura Journal of Forensic Medicine and Clinical Toxicology, 28(1): 25-42.

Sikary AK, Dixit S \& Murty OP (2017): Fatal carbon monoxide poisoning: A lesson from a retrospective study at All India Institute of Medical Sciences, New Delhi. Journal of Family Medicine and Primary Care, 6 (4): 791-794.

Stræde, M., \& Brabrand, M. (2014). External validation of the simple clinical score and the HOTEL score, two scores for predicting shortterm mortality after admission to an acute medical unit. PloS One, 9(8), e105695.

Stucki D \& Stahl W (2020): Carbon monoxide - beyond toxicity? Toxicology Letters, 333:251-260.

Subbe C, Durham L, Welch J \& Oglesby K (2010): Score to door time: a benchmarking tool for rapid response systems. Critical Care, 14(1): 263.

Subbe CP, Davies RG, Williams E, Rutherford P \& Gemmell L (2003): Effect of introducing the Modified Early Warning score on clinical outcomes, cardio-pulmonary arrests and intensive care utilisation in acute medical admissions. Anaesthesia, 58(8), 797-802.

Subbe CP, Jishi F \& Hibbs RAB (2010):The simple clinical score: a tool for benchmarking of emergency admissions in acute internal medicine. Clinical Medicine (London, England), 10(4): 352-357.

Tabrizian K, Khodayari H, Rezaee R, Jahantigh H, Bagheri G, Tsarouhas K \& Hashemzaei M (2018): Magnesium sulfate protects the heart against carbon monoxide-induced cardiotoxicity in rats. Research in Pharmaceutical Sciences, 13(1): 65-72.

Wang IJ., Yeom SR., Park SW, Lee SH, Han SK, Park SC, Ryu JH \& Hwang SY (2019): Poison severity score and sequential organ failure assessment score: Carbon monoxide poisoning prognosis. PloS One, 14(3), e0212025-e0212025.

Xie X, Huang W, Liu Q, Tan W, Pan L, Wang L, Zhang J, Wang Y \& Zeng Y (2018): Prognostic value of Modified Early Warning Score generated in a Chinese emergency department: a prospective cohort study. BMJ Open, 8 (12): e024120.

\section{تقييم أنظمة قياسية مختلفة للتبؤ بنتائج التسمم الحاد بأول أكسيد الكربون}

'أميرة السيد الهواري وغادة عطية صاجة'

\section{الملخص العربي}

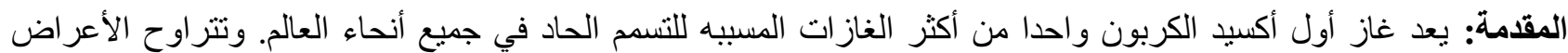

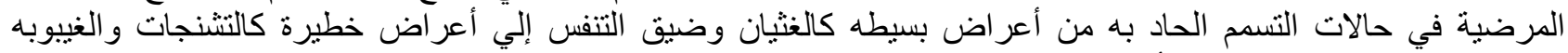

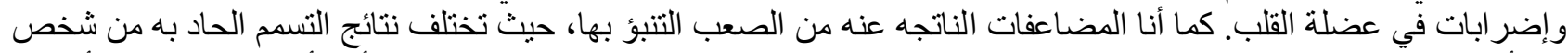

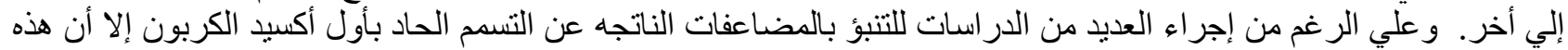
الدر اسات اعتمدت علي نتائج التحاليل المعمليه و الأشعه التصويريه التي قد يتعذر نوفرها في جميع الأحيان.

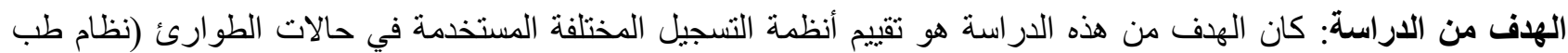

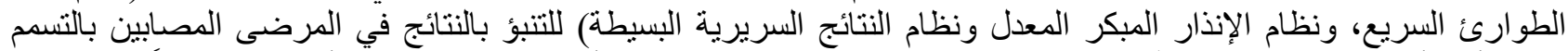

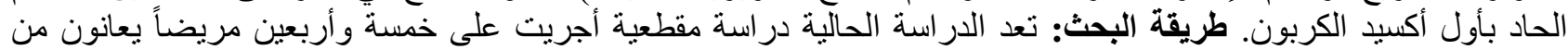

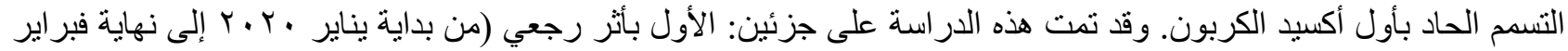

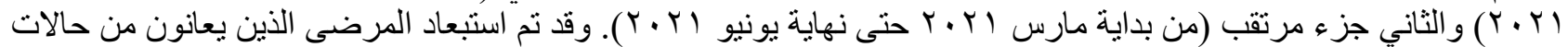

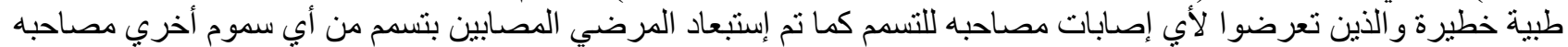

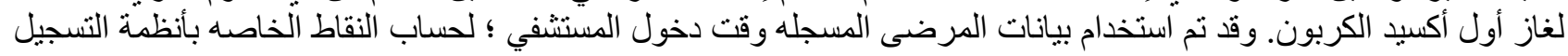

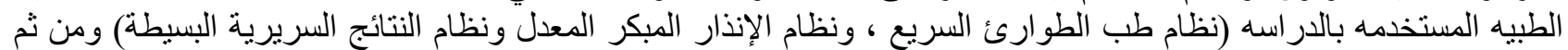

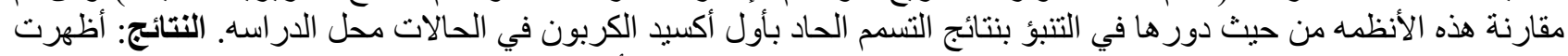

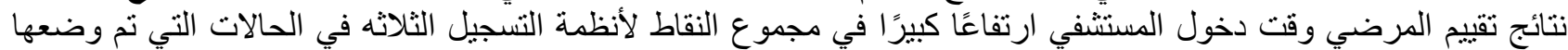

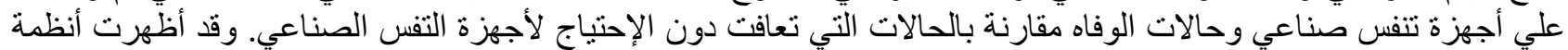

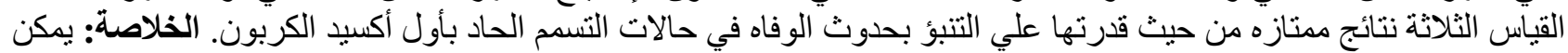

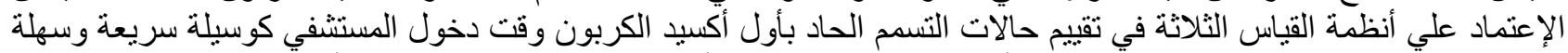

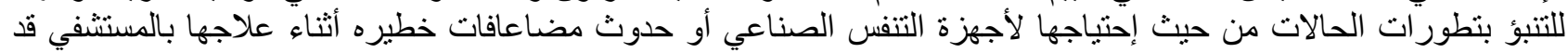

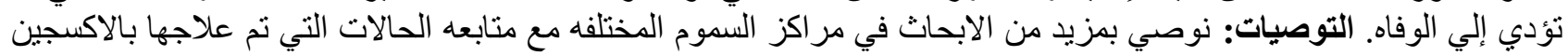
عالي الضغط وذللك لتاكيد نتائج الدرأسه الحالية. 